\title{
ENGENHARIA SOCIAL DE POPPER: UMA POSSIBILIDADE PARA REFORMAS POLÍTICAS NAS SOCIEDADES DEMOCRÁTICAS, CASO DE MOÇAMBIQUE
}

\author{
Popper's Social Engineering: a Possibility for Political Reforms \\ in Democratic Societies, Case of Moçambique \\ Nito Luis Magesso \\ CAP Universidade Eduardo Mondlane, Maputo \\ nitomagesso@gmail.com
}

\begin{abstract}
Resumo:
A compreensão de liberdade, igualdade e desenvolvimento socioeconómico e político, passa de uma democracia consolidada. Este artigo procura analisar a engenharia social de Popper e mostrar como esta constitui uma possibilidade de reformas políticas nas sociedades democráticas, olhando para o caso de Moçambique. Através do método bibliográfico, os resultados deste estudo mostram que a democracia em Moçambique precisa de um aperfeiçoamento que vai desde a liberalização da democracia, as instituições que se fundam nos substratos culturais e na justiça social. E, a separação dos poderes: executivos, legislativo e judiciário é um elemento crucial nessa abordagem, bem como o debate crítico intersubjectivo e planeamento gradual.
\end{abstract}

\section{Palavras-chave:}

Engenharia social, Reformas Políticas, Liberdade, desenvolvimento.

\begin{abstract}
:
The understanding of freedom, equality and socio-economic and political development is more than a consolidated democracy. This article seeks to analyze Popper's social engineering and show how it constitutes a possibility for political reforms in democratic societies, looking at the case of Mozambique. Through the bibliographic method, the results of this study show that democracy in Mozambique needs improvement, ranging from the liberalization of democracy, to institutions that are founded on cultural substrates and social justice. And, the separation of powers: executives, legislative and judiciary are a crucial element in this approach, as well as critical intersubjective debate and gradual planning.
\end{abstract}

Keywords:

Social Engineering, Political Reforms, Freedom, Development. 
Recibido: 19/05/2021

Aceptado: 01/07/2021

\section{INTRODUÇÃO}

Moçambique tem uma história de liberdade e democracia muito jovem, como podemos ler em Mazula (2006: 60) a história da democracia em Moçambique, configurou-se a partir de 1990, com o fim da guerra civil, a revisão constitucional e da assinatura dos acordos de Lusaka. A partir desse momento, Moçambique vive um novo cenário sociopolítico, registando-se novos rumos para a consolidação e fortalecimento de um Estado de direito. O país passou a consagrar-se como um regime político guiado por ideais democráticos onde todos os cidadãos são chamados a participar activa e permanentemente na vida política. Apesar da afirmação da democracia, hoje tão pouco se pode falar dos elementos que caracterizam a democracia razoável, para a liberdade e desenvolvimento do país. Assiste-se um novo cenário sociopolítico questionável, logo percebe-se que a democracia em Moçambique apresenta grandes dificuldades, basta olharmos:
A pobreza, a fome, o fechamento político do Estado, a visão monopartidária, a corrupção, a iliteracia de adultos, a descriminação étnica, racial, sexual e religiosa, a exclusão social, a democracia induzida, a divida externa e a gerontocracia (governo de velhos), todas elas amordaçam, anquilosam e matam a democracia. Gangrena mais a democracia o tipo de corrupção que chamaria de corrupção elitizada: aquela praticada por alguns segmentos da elite política absolvem-se a si mesmos maquinando concursos públicos e aparentando transparência do processo que uma economia de mercado exige, mas subtilmente orientados para benéficos pessoas (Mazula, 2006: 67).

Destacam-se ainda as pseudopolíticas de governação e estratégias de desenvolvimento, a inexistência de um princípio claro de trabalho que rege a governação de cada novo governo, dado que nota-se uma mudança total ou parcial à cada eleição do mesmo, regredindo cada vez mais, a inclinação aos princípios do partido, isto é, a partidocracia (Ngoenha) a corrupção justificada pela pobreza e estruturas alargadas da família, altos níveis de analfabetismo, a prostituição crescente, o crescimento económico baixo, desemprego, criminalidade, guerra civil protagonizada pelas duas maiores forças partidárias do país, o terrorismo na região norte de Moçambique, ausência de debate crítico intersubjectivo, a liberdade de expressão a indiferença ou resposta negativa pelo pensar diferente, demonstram uma falta de liberdade enquanto condição fundamental para o desenvolvimento. Como consequência regride-se para o sistema Marxista-leninista, dado que não se verificam traços que fundamentam a democracia. Além destes, existem muitos outros males que um país não democrático e pobre pode deparar-se. Por que ainda havendo níveis elevados de pobreza, existem pessoas (um número restrito), com muita posse e abundância? por que a riqueza não é bem distribuída e, por que ela está só na elite 
política? Esse é um indicador positivo, que a nossa democracia está longe de responder os anseios do povo, mas sim de um grupinho. Quem olha a realidade moçambicana, vê que há uma desigualdade social exacerbada o que pressupõe que as necessidades básicas não foram ainda supridas (educação, saúde, o problema de alimentação e segurança), esses elementos são justificados pela má governação e ausência da democracia.

A democracia coadjuvada de boa governação, traz bons resultados, sobretudo na melhoria das condições de vida da população. O Estado não tem interesses privados, grupais ou étnicos, mas tem interesse comum, sobretudo num país como nosso marcado pela diversidade étnica. O objectivo do Estado é gerir da melhor maneira a coisa pública com intuito de proporcionar a qualidade de vida dos cidadãos. E por causa do interesse privado (individualismo) que o país vem registrando desigualdades sociais agudizadas. Entretanto, é fundamental destacar que a fórmula básica da democracia é o equilíbrio entre o universal, o particular, a razão e o povo (Touraine, 2008: 56).

\title{
A DEMOCRACIA E A IGUALDADE
}

O mundo conheceu várias formas de organização política, como é o caso das Monarquias, aristocracias, tirania, oligarquia, demogagonia, democracia, ditaduras (totalitarismo), autocracias etc., só para citar alguns exemplos. Apesar disso, só a democracia constitui um princípio razoável, por abrir a possibilidade da igualdade dos cidadãos, e porque ela abre espaço para que os mesmos decidam sobre o rumo da nação. Além do tal, a liberdade parece ser possível dentro deste sistema político. Por isso, para Popper (1974: 98) a democracia é imperfeita tanto quanto os outros regimes, mas ela é a pior, à excepção de todas outras, pelas seguintes razões:

\begin{abstract}
A democracia é aquele tipo de governo no qual as instituições fornecem meios para a substituição institucional dos governantes, sem recurso ao uso da violência, quando eles mostrarem-se incompetentes; O indivíduo tem direito sobretudo da liberdade de pensamento (pode expor suas ideias, para a mudança de certos aspectos). Mas em caso dela se transformar no seu contrário, então o seu remédio será derrubá-la com uso de violência (Popper, 1974: 167).
\end{abstract}

A democracia pode apresentar-se de várias formas. Mas de forma geral, podemos agrupar em três grandes tipos: a democracia directa, indirecta (parlamentar), e liberal: a democracia directa é aquela em que o poder é exercido pelo povo, sem intermediário. Como afirma Bobbio (1984: 41) a democracia consiste na participação de todos os cidadãos em todas as decisões a eles pertinentes. Todos decidem sobre tudo. Realçar que, este modelo político é aplicável apenas a populações e territórios pequenos (é o caso de Atenas, na Antiguidade). Actualmente, não sendo possível pelo grosso número populacional, a maioria das democracias actuais, são caracterizados por uma forma de democracia indirecta, em que as decisões políticas não são tomadas directamente pelos cidadãos, mas por representantes eleitos por eles ou pelo presidente; a denominada democracia indirecta, parlamentar ou representativa consiste geralmente na delegação de poderes a um parlamento eleito, esta radica-se na democracia autoritária, que é aquela na qual há um único indivíduo, que detém o 
conjunto de poderes por determinado tempo, ou vitaliciamente. Por fim, temos o modelo de democracia liberal ou democracia constitucional, a chamada Republicana, a mais recente democracia ocidental. É aquela que define o estatuto do cidadão, antes de mais, pelos direitos positivos face ao Estado e aos outros cidadãos. O cidadão goza da protecção do Estado na medida em que se confina aos limites traçados pela lei. Ainda os direitos políticos e direitos civis têm a mesma estrutura. Deste modo, em sociedades sempre mais complexas como são as modernas sociedades, a democracia directa é algo materialmente impossível. Daí que é difícil falar de uma verdadeira democracia nos dias de hoje, porque ela já não proporciona a participação directa de povo, conforme afirma Rousseau:

Para erguer uma verdadeira democracia, é requer muitas condições difíceis de serem reunidas. Em primeiro lugar um Estado muito pequeno, no qual ao povo seja fácil reunir-se e cada cidadão possa facilmente conhecer todos os demais; em segundo lugar, uma grande simplicidade de costumes que impeça a multiplicação dos problemas e as discussões espinhosas; além do mais, uma grande igualdade de condições e fortunas; por fim, pouco ou nada de luxo. (Rousseau apud Bobbio, 1984: 41).

Não havendo essas condições actualmente só é possível assistir a democracia representativa. A nossa tarefa como filósofos é procurar repensar e aperfeiçoar cada vez mais a democracia, para que tenhamos uma verdadeira democracia. Aquela que procura prover a liberdade, a igualdade e o desenvolvimento de todos na polis. Popper (1974: 167), por exemplo, é um pensador que procura aperfeiçoar a democracia com base na sua engenharia social. Na sua teorização, ele começa por colocar em causa a democracia representativa. Para Popper (1974) a democracia não pode ser representativa, porque não exprime a vontade do povo e favorece a minoria. Para o filósofo, o ideal seria a democracia liberal. Nestes moldes, Popper (1974) partilha a ideia segundo a qual, a soberania não pode ser representada, mas sim directa, isto é, o cidadão deve participar directamente, para que não se favoreça a minoria ou para que a democracia não se torne uma ditadura.

\section{DEMOCRACIA COMO CONJUNTO DE INSTITUIÇÕES}

Apesar da existência de várias formas de democracia e, embora inspirando-se da experiência ateniense da democracia, o ocidente não produziu simetricamente, cada país foi, a partir dela, construindo a sua democracia (Mazula, 2006: 62). Na actualidade a democracia não pode ser concebida simplesmente como governo do povo, tal como fora concebido na Grécia antiga (Atenas). Na compreensão de Popper a democracia deve ser entendida como um conjunto de instituições. Isto significa que as instituições (os tribunais, os ministérios, etc.) devem ser fortes, e não os políticos. O que se tem notado nos países em vias de desenvolvimento, especificamente nos países africanos, os políticos possuem mais poderes em relação às instituições, e por consequências assiste-se abusos de poderes défices de frear, o que cria de certa forma uma fragilidade nas instituições e na democracia. Por isso, as instituições devem ter poderes suficientes para regular as actividades dos políticos e não o contrário.

Quando Popper afirma que a democracia deve ser vista como um conjunto de instituições, ele não pretende descartar por completo a ideia de que a democracia é 
governo de povo para povo, ele pretende que antes de tudo, sejam valorizadas as instituições, porque são elas que vão proteger os direitos dos povos. Se as instituições forem bem fortes, não permitirão a corrupção, então será possível falar uma democracia, aquela que valoriza o direito e a vontade do povo e que pode mudar o governo sem uso da violência. Se as intuições não forem bem fundamentadas, a democracia apresentará enormes dificuldades, porque não permitirá a liberdade dos povos, e por conseguinte transformar-se-á numa tirania. Por isso, os regimes democráticos constituem uma salvação dos povos contra a ditadura.

Na óptica de Popper, para que haja instituições fortes, elas devem se fundar nas tradições, porque "As instituições tradicionais estão na base de um Estado democrático, por isso, a cultura, a tradição e as instituições sociais são elementos para o desenvolvimento" (Popper, 1945: 86). E que por sinal produzem nossos valores (Popper,1974: 265-6). Apesar disso, Popper entende que as tradições também influenciam e limitam nossa liberdade criativa e no nosso poder para exercitar o racionalismo crítico. Para tal, é preciso que as tradições se conectem as instituições com intenções e avaliações do indivíduo, uma vez que existem valores regulativos dentro das instituições e tradições, mas tudo isso é criticável e mutável, por isso, nossa racionalidade deve consistir em criticar tais valores (Popper, 1945: 86). Contudo, as instituições e as tradições têm em vista a regular o debate crítico. Por essa razão, Nyasani (2010: 94), entende que o desenvolvimento em África deve-se aos problemas culturais e sociopsicológicos associada à questão de que a África como uma sociedade inacessível, isto é, com tradições morais e práticas culturais intocáveis. Apesar disso, verifica-se uma submissão à modernidade ocidental. A África deve lutar pela auto-alienação, pois a cultura, na visão de Nyasani, exalta e eleva a alma humana para o pico de uma harmonia psicológica e espiritual e também, a uma reconciliação mental, predispõe a sociedade a uma realização de actos de máxima notabilidade e honra. "A tradição é o momento de alteridade e autonomia do Africano, pois a tradição é um elemento que permite aculturar um conjunto de costumes, valores, crenças, rituais, normas e leis, por um indivíduo ou grupo social (Ilungu, 1998: 78) ". A tradição constitui um elemento necessário para inventarmos a nossa democracia, uma vez que os modelos Ocidentais permitem o cronismo, a corrupção, disparidades a nível de sofisticação intelectual, a tecnologia ilusória do Ocidente, são alguns dos exemplos que Nyasani (2010: 137) nos apresenta como característicos dos modelos Ocidentais que criam um efeito de retracção no desenvolvimento de África. Aliado a esta perspectiva, Ngoenha (2004: 159-189), afirma que a nossa democracia é falsificada devido a dependência de uma cultura de Estado que se espelha num sistema ocidental. Daí que o filósofo propõe uma perspectiva da qual chama de contracto cultural que consiste em as instituições melhorar os modelos institucionais da democracia deveriam mudar e serem aculturados, haurir a sua legitimidade dos imaginários colectivos, das linguagens das pessoas, da maneira como eles concebem a sua vida social e colectiva.

Esse contracto cultural na visão do filósofo moçambicano não é a reabilitação das instituições ancestrais, é a combinação de dimensões axiológicas e institucionais da democracia. Trata-se de ressuscitar a tradição de maneira crítica (Popper, 1974; Ngoenha, 2004). Significa que temos que olhar para trás para aprender o que o passado tem de bom e recusar o que não nos convém. Temos que construir a nossa 
democracia, que depende de uma aculturação das ideias democráticas às diferentes maneiras com as quais os povos entendem e interpretam a sua vida social (Ngoenha, 2004: 86). No entanto, há uma necessidade de reformarmos as nossas instituições por forma a inventar uma democracia que seja um governo do povo no respeito pelo povo, das suas representações culturais e dos seus imaginários colectivos e que possa garantir as condições básicas a todos. Neste caso, o Estado deve procurar sempre promover o bem-estar dos cidadãos e não o contrário. É necessário ter-se em conta que o desenvolvimento enquanto liberdade deve estar ligado à democracia, por razões que já explicamos. Contudo, temos que levar a sério os nossos aspectos culturais e temos que inventar um modelo institucional que se inspire nos nossos substratos culturais. Porque, não são as culturas que se têm de adaptar a todo o custo a modelos que responderam ao génio próprio de certos povos num determinado momento da sua história, mas os modelos que se tem forjado a partir das culturas. Isto significa que nós temos que inventar um modelo de sociedade que nos seja próprio, um modelo capaz de mobilizar o conjunto de cidadãos a participarem não só nas eleições, mas na vida integral da sociedade (Ngoenha; 2004: 117).

\section{LIBERALISMO E DEMOCRACIA}

O liberalismo é uma forma de governo que deve ser intrínseca a democracia na actualidade, uma vez que este modelo valoriza o princípio individualista. Isto significa que na democracia liberal qualquer cidadão pode decidir os rumos da nação, e as instituições devem abrir sempre o espaço para proporcionar a liberdade e igualdade de todos homens, porque estes são dois grandes valores, inalienáveis do homem. Os contratualistas afirmam que liberalismo, por proporcionar a liberdade dos cidadãos, apresenta uma das cláusulas necessária para a manutenção da paz após a perda no estado natural. Por isso, deve-se entender que o Estado liberal não é uma concessão, mas o resultado de um acordo de vontades. Nasce de uma contínua e progressiva erosão do poder absoluto ou de rupturas revolucionárias, justificando-se como o resultado de um acordo entre indivíduos que pretendem estabelecer uma convivência pacífica e duradoura. Assim, a doutrina liberal deve permitir que sejam garantidos os assim denominados direitos de liberdade, de opinião, de expressão das próprias opiniões, de reunião, de associação, etc. Seja qual for o fundamento filosófico destes direitos, eles são o pressuposto necessário para o correto funcionamento dos próprios mecanismos que caracterizam um regime democrático (Bobbio, 1984: 20). Para Sen (2000: 181) a fase actual da democracia é de desenvolvimento e, o mecanismo mais seguro para um Estado de direito ${ }^{1}$ seria a democracia liberal, isto porque o liberalismo segundo Bobbio (1984: 687) é justamente o critério que distingue a democracia liberal das democracias não liberais (plebiscitária ${ }^{2}$, populista, totalitária, e o Socialismo Marxista, uma vez que estes defendem a forte intervenção do Estado), também porque

\footnotetext{
${ }^{1}$ Um Estado de direito é aquele em que os poderes públicos são, todo cidadão pode recorrer a um juiz independente para fazer com que seja reconhecido e refutado o abuso ou excesso de poder.

${ }^{2}$ A democracia plebiscitária é a convocação dos eleitos do pais a provar ou rejeitar questões relevantes antes da existência de lei ou do acto administrativo. Assim, a população diz se quer ou não que ele seja aprovado.
} 
o liberalismo concebe um Estado na qual tem poderes e funções limitadas. Nestes moldes, para que haja uma boa democracia é necessário que estes dois regimes sejam interdependentes, conforme nos dá a perceber o filósofo italiano.

(...) O Estado liberal é o pressuposto (...) jurídico do Estado democrático. Estado liberal e estado democrático são interdependentes em dois modos: na direcção que vai do liberalismo à democracia, no sentido de que são necessárias certas liberdades para o exercício correto do poder democrático, e na direcção oposta que vai da democracia ao liberalismo, no sentido de que é necessário o poder democrático para garantir a existência e a persistência das liberdades fundamentais. Em outras palavras: é pouco provável que um Estado não liberal possa assegurar um correto funcionamento da democracia, e de outra parte é pouco provável que um Estado não democrático seja capaz de garantir as liberdades fundamentais. A prova histórica desta interdependência está no fato de que estado liberal e estado democrático, quando caem, caem juntos (Bobbio, 1992: 33-34).

Entretanto, deve-se em primeira instância exaltar o indivíduo como um ser capaz de actuar livremente dentro sociedades (democracia liberal), nas quais os valores como liberdade, igualdade, alteridade e tolerância são consideradas como condições para que um país possa chegar a uma sociedade democrática e para alcançar um certo estágio de desenvolvimento. Contudo, o fulcro da democracia liberal continua a ser "como a única aspiração política corrente que constitui o ponto de união entre regiões e culturas diversas do mundo todo" (Fukuyama, 1992: 12). Por exemplo, a unidade nacional em Moçambique pode ser reforçada com este desiderato político. Entretanto, a democracia que pretendemos em nosso país deve aperfeiçoar um quadro institucional democrático liberal, isto ajudará de acordo com Popper (1974: 167), a vivermos em uma democracia constituída por instituições, e que permitem derrubar o governo sem recorrer à violência, isto é, sem chegar à supressão física de seus componentes.

A sociedade liberal é aquela que está aberta a mais visões filosóficas e religiosas do mundo, mais valores, e a mais partidos (Popper, 1974: 16). Porque são esses partidos que fazem a democracia operar, o que Morin (1989: 93) chama de organização viva. Esta existe quando há elementos antagónicos, e que os mesmos dialogam entre si. Para Popper, uma sociedade liberal está aberta por causa da falibilidade do conhecimento humano e pelo politeísmo de valores. Na análise de Espada (2008: 47), sobre a filosofia política de Popper afirma que seria inútil, falar de democracia excluindo a liberdade política, a participação dos indivíduos sociais nos projectos de desenvolvimento, a tutela das liberdades individuais e a crítica racional dentro do sistema de governação. Na democracia liberal requer uma gestão socialmente responsável dos problemas, exigindo uma abordagem rigorosa, e profissional, precisamente para identificar alternativas de solução a esses problemas. O importante no Estado liberal de acordo com Ngoenha (2013: 54) é a segurança garantida pelas leis, não contra o Estado, porque as leis determinam a conduta da polis.

Desta forma podemos afirmar que a democracia liberal, deve ser entendida como a única forma de governo inclusivo que encoraja o cidadão comum a participar nos 
projectos conducentes aos progressos institucionais. Para Popper (1974: 93), uma democracia constitucional e liberal é melhor do que as outras, na política ou na ciência, na qual as pessoas com mentes livres podem discutir as diferentes teorias que nada mais é do que tentativa de solução para os males da sociedade. Entretanto, o funcionamento da democracia depende fundamentalmente da medida da compreensão do facto que um governo busca seu poder para estabelecer a tolerância por parte de um terceiro e colocar à margem da lei, de modo que o cidadão não tenha direito, como também obrigações. É democrática a sociedade que possui instituições baseadas numa sociedade aberta. Esta deve estar fechada apenas para os intolerantes.

\section{INTERVENCIONISMO ECONÓMICO E O PRINCÍPIO PROTECCIONISTA DO ESTADO}

O Estado liberal pretendido na democracia, deve ser caracterizado pelo intervencionismo económico. A questão do intervencionismo económico, foi discutido no contexto do liberalismo defendido primeiramente por Locke, Mill, e Bentham, no qual estava ligado ao capitalismo, eles defendem uma ampla gama de pontos de vista, dependendo de sua compreensão desses princípios mas, em geral o liberalismo apresenta como ponto principal a defesa da liberdade política e económica, isto é, reinava o provérbio cada um por si, Deus para todos. Marx, também está nesta linha liberal, na medida que ele atribui muita força ao poder económico em relação ao poder político. Karl Popper, ao contrário, pensa que o poder político é o mais importante ou, mais exactamente, que o poder político pode tornar-se o mais importante, a ponto de controlar o poder económico. Neste sentido, o fulcro é que os liberais supra, assim como Marx e Hayek, são contrários ao forte controle do Estado na economia e na vida das pessoas. Esse ponto de vista, Popper chama de capitalismo sem entraves. Por isso, Popper é adverso a este liberalismo. Ele toma a postura do economista britânico Keynes $(1983)^{3}$ que defende a ideia segundo a qual no liberalismo é necessário a intervenção do Estado (neoliberalismo). A esta perspectiva Popper chama de intervencionismo económico do Estado, numa palavra, não se pode ser inimigo da intervenção do Estado na vida social.

Devemos reclamar que o capitalismo sem entrave dê lugar a um intervencionismo económico. As instituições socias devem ser asseguradas pelo poder do Estado, para a protecção dos economicamente fracos contra os economicamente fortes. O estado deve cuidar de que ninguém em entendimento não equitativo por medo da fome ou de ruina económica. Isto sem dúvida, significa que o princípio de não intervenção, de um sistema económico irrestrito, tem de ser abandonado; se quisermos que a liberdade seja salvaguardada, devemos então exigir que a política

\footnotetext{
${ }^{3}$ O liberalismo Clássico (defendido por Locke, Stuart Mill e Bentham), defende que o Estado não deve intervir na economia, ou deve intervir mínimo. Mas, Jonh Keynes, economista britânico, foi um dos que, no início do século XX, mais defendeu a intervenção do Estado na economia. Depois da depressão dos anos trinta do século passado, aquele economista defendeu que o mercado não era capaz de se auto-regular, pelo que o Estado deveria intervir equilibrando a economia, nomeadamente através do investimento público e da aplicação de medidas que interviessem na diminuição do desemprego.
} 
de liberdade económica ilimitada seja substituída pelo planejado intervenção económica do estado (Popper; 1974: 130-2).

No entanto, a preocupação básica do Estado devia ser sempre a liberdade, e a igualdade, isto é, a protecção de todos os cidadãos e de todos os males que podem surgir. Nestes moldes, a intervenção social seria um mecanismo para corrigir a desigualdade económica, começando pela restrição da liberdade e da desigualdade. Embora Popper defenda o intervencionismo, considera- o muito problemático a sua postura em relação ao intervencionismo do Estado, porque deve se ter muita cautela. Ele julga que "o poder do Estado deve sempre permanecer um mal perigoso, ainda que necessário" (Popper, 1982: 130). E, adverte contra o que chama de paradoxo do planeamento estatal ou o paradoxo da liberdade4, por isso ele afirma:

Se planejarmos demais, se dermos demasiado poder ao Estado, a liberdade estará perdida e isso será o fim do planeamento, a intervenção do Estado deve ser limitada ao que for necessário realmente para a protecção da liberdade (...) Só a liberdade pode tornar segura a segurança. (Popper, 1983: 130-137).

Há necessidade de se dar os poderes políticos e económicos ao Estado para garantir a protecção (princípio proteccionista), porque se não o fizermos o poder estará nas mãos alheias e, por conseguinte, cair-se-á num Estado natural de Hobbes. Ou como Popper afirma: É claro que a ideia de um mercado livre é paradoxal. Se o Estado não intervier, então poderão intervir outras organizações semipolíticas, como monopólios, trusts, sindicatos, etc., reduzindo a uma ficção a liberdade do mercado (Popper, 1982: 366). Foucault concorda com está perspectiva de Popper ao afirmar que a economia de mercado social, a regulação dos preços não deve ser executado pelo mercado, mas pelo Estado, porque ela é a única referência da economia racional.

No entanto, a intervenção do Estado visa garantir as regras concorrenciais do mercado, e a concorrência que impulsionam o desenvolvimento. Porquanto essa intervenção não pode ser demais. Porque de acordo com Popper (1982: 137), não se pode dar demasiado poder ao Estado, isto é, é necessário uma vigilância. Não podemos nos depravar porque, se relaxarmos a nossa vigilância (do controlo político), e não fortalecermos as nossas instituições democráticas, ao mesmo tempo que damos maior poder ao Estado, através do planeamento intervencionista, então perderemos à nossa liberdade e será o fim do planeamento. Em caso de existir excesso de intervencionismo económico do Estado, Foucault (2008), enrobustece a perspectiva de Popper encorajando que é necessário recorrer a analítica de $\operatorname{poder}^{4}$ que segundo

\footnotetext{
${ }^{4}$ A partir da analítica de Poder Foucault sustenta que a representação do poder como coisa ou posse e não constituir o resultado da realização de uma potência da qual uns seriam dotados e outros não; até mesmo sua identificação com uma instituição, estas são somente sedimentações derivadas da confluência de forças infinitesimais e estratégias plurais actuantes no tecido societário. Na analítica do poder, Foucault afirma que o poder não deve ser pensado como fundamentalmente emanado de um ponto (em geral, identificado com o Estado). Devese ter, pois, em mente, na procura de uma compreensão da dinâmica das relações de poder, a ideia de uma rede. Porque o poder é um feixe de relações mais ou menos piramidalizado, mais ou menos coordenado. o que caracteriza o poder (do estado) é que traz à acção relações entre indivíduos (ou entre grupos). Para não nos deixar enganar; só podemos falar de estruturas
} 
ele serve de uma crítica ao Estado intervencionista excessivo. Além do mais, Popper corrobora com o neoliberalismo sobre a necessidade de um Estado interventivo na economia, para que haja uma economia planificada: uma economia centrada em torno de um aparelho administrativo que toma o essencial das decisões na ordem da economia, atribuindo os recursos raros, estabelecendo o nível dos preços e garantindo o emprego pleno. Deste modo, a defesa do intervencionismo económico parece coerente e tem sido confirmada em países de capitalismo adiantado, particularmente nos países ocidentais, onde o Estado tem desempenhado funções muito importantes na protecção dos desprivilegiados, ao mesmo tempo que parece se desenvolver transformação ética nas populações, no sentido da responsabilidade social, da solidariedade e subsidiariedade em relação outros países. Mas a potência da política parece muito questionável em países menos desenvolvidos, sendo isso notório de modo particular em Moçambique em que esforços de governos que parecem bemintencionados têm sido incapazes de mudar o quadro de exploração e miséria da sociedade. A concepção da democracia liberal deveria corresponder a uma ideia de Estado, na qual possui poderes de intervir mais com funções limitadas (freios e Contrapesos) principalmente providenciar a liberdade de pensamento. Deve contrapor-se tanto ao Estado absoluto como ao Estado social.

\section{FREIOS E CONTRAPESOS}

Popper pensa que as nossas instituições podem ser aperfeiçoadas através da possibilidade de separação de poderes do Estado, como forma de proteger as liberdades individuais. Historicamente, este princípio surgiu na evolução do pensamento de Aristóteles, na sua obra, A Política, onde o filósofo isolou três tipos distintos de actos estatais, quais sejam: "o acto deliberativo, o executivo e os actos judiciais". Embora ele não tenha tratado da funcionalidade dessa separação; não instituiu a independência entre poderes, o que só fora feito posteriormente. Tal estudo, influenciou os Filósofos Modernos, principalmente Montesquieu. A teoria de separação de poderes significou uma resposta ao Estado absolutista e totalitário, no qual todo o poder se encontrava nas mãos da Monarquia. Diante da preocupação com a garantia aos cidadãos de liberdade perante os ocupantes do poder, criou-se o Estado Liberal, embasado no princípio da divisão de poderes, objectivando limitar o poder político, para que haja o Estado mínimo.

Este princípio, Popper denominou de princípio de "Freios e contrapesos" (Checks and Balances). Ou seja, o sistema de separação de poderes é associado à ideia de Estado Democrático liberal é que deu origem a uma engenhosa construção doutrinária, conhecida como sistema de "freios e contrapesos". Mas uma vez, este princípio vem enrobustecer o Estado liberal, conforme demos a anteriormente. Para Popper (1957: 89) este princípio surge como alternativa às teorias da soberania geral e da democracia particular, para que o poder não tome uma feição instrumental. Esta doutrina, além de identificar quais seriam as funções exercidas pelo Estado, como já o fizera Aristóteles, também defende a necessidade de que o exercício de cada uma

ou de mecanismo de poder na medida em que supomos que certas pessoas exercem poder sobre outras. O termo poder designa relacionamentos entre parceiros. 
dessas funções seja atribuído a diferentes titulares. A ideia central desta teoria é de servir de um mecanismo eficiente que impeça o poder exercido sem limites. Por isso, torna-se necessário na política a separação dos poderes, para que seja o poder descentralizado e, dessa forma, alcançar uma forma de governo que garanta as liberdades individuais.

A estratégia de Popper com este princípio de "freios e contrapesos" era de postular a ideia segundo a qual o espaço político deveria ser organizado de forma que "o poder se encarregasse de controlar o próprio poder" e a soberania deveria ser deslocada das mãos do monarca para as mãos do povo. Neste sentido, a não separação de poderes implicaria ausência de democracia. Para Ngoenha (2014: 174), a única maneira de atenuar a invasão da vontade do poder humano, na gestão das coisas públicas, é preveni-la. Isto supõe que se deve limitar e dividir o poder. Estes são elementos crucias quando se pretende controlar o controlador. Significa que devemos exigir sempre em primeiro lugar na democracia que haja uma separação total entre os três grandes poderes do Estado (o executivo, o legislativo e o judiciários). Este seria o primeiro passo, que nos permitiria controlar o poder. Implicaria também a mudança não das pessoas, mas sim, do sistema, porque se o sistema for bem definido não permitirá o abuso do poder. Um governo em que há concentração de poder num só indivíduo, pode confundir-se num autoritarismo, monarquia ou mesmo totalitário. Isto acontece porque ninguém tem autoridade ou poder de julgar este indivíduo que detém o poder. O princípio de separação de poderes Segundo Ngoenha (2004: 120), tem por objectivo instaurar o Estado de direito, isto é, proteger o cidadão contra os abusos do poder. Deste modo, a limitação do poder estatal dará origem a liberdade individual, que é o fundamento da doutrina liberal e característico da sociedade aberta. Em suma a democracia só pode existir segundo Touraine (2008: 162) se a liberdade dispuser de um espaço indestrutível, se o campo do poder for mais limitado que o da organização social e o das escolhas individuais.

\section{INSTITUIÇÕES E JUSTIÇA SOCIAL}

Não estamos condenados a regimes autoritários. É preciso conceber uma democracia que repouse sobre a justiça social e que defendem o sujeito humano contra a dupla impersonalidade do poder absoluto ou do totalitarismo. Deste modo, a justiça social é outro desafio que se propõe para o melhoramento das instituições (democracia). Significando que, a democracia deve antes de mais, fundamentar-se na ideia de Justiça social, porque, conforme afirma Rawls (2000: 3) a justiça é a primeira virtude das instituições sociais. As instituições sociais devem antes do mais, se fundar na justiça social, baseada em acordo de vontades, por forma a não favorecer a violação da liberdade e bem-estar dos cidadãos. Isso pressupõe o bom funcionamento das instituições sociais. Esse funcionamento depende da crítica ou do falseficacionismo, como quer Popper e Rawls. "uma teoria, deve ser rejeitada e revista se não é verdadeira; da mesma forma as leis e instituições, por mais eficaz e bem organizado que sejam devem ser reformadas ou abolidas se são injustas" (Rawls, 2000: 4). A partir dessa perspectiva, reafirmamos que as instituições devem sobreviver com base na aceitação da crítica, e devem ser revisitadas, reformadas e reformuladas ou abolidas se forem injustas. A justiça não pode se encarar ao modelo platónico, aristotélico ou hobbesino: para o primeiro (Platão) a justiça seria a virtude que atribui a cada um a 
sua parte, mas esse senso de justiça seria exercido tanto no interior do homem como no seio da Cidade-Estado, onde os homens se relacionam. Ao contrário, o segundo (Aristóteles), pensara a justiça como parelha a uma suposta igualdade proporcional, mais próximo de Hobbes, que concebera a justiça independentemente da igualdade entre os homens, tendo em vista que a importância da justiça estará no respeito ao pacto social. Mas devemos pensá-la na maneira de Rawls que entende a justiça como equidade. Para Rawls a justiça como equidade deve ser baseado em dois princípios da justiça. E esse princípio expressa-se da seguinte forma:

Primeiro: cada pessoa deve ter um direito igual ao mais abrangente sistema de liberdade básicas iguais que seja compatível com um sistema semelhante de liberdades para as outras; Segundo: as desigualdades socias e económicas devem ser ordenadas de tal modo que sejam ao mesmo tempo. a) Consideradas como vantajosas para todos dentro dos limites razoáveis, e b) vinculadas a posições e cargos acessíveis a todos (Rawls, 2000: 4).

No entanto, a justiça social e a sua realização supõe, pelo menos, a criação de mecanismos susceptíveis de impedir o desenvolvimento de desigualdades demasiado grandes na sociedade. Por essa razão Rawls (2000: 4), concordando com o ideal popperiano nega que a justiça seja, a perda de liberdade de alguns se justifique por um bem maior partilhado por outros. Rawls não permite ainda que os sacrifícios impostos a uns poucos tenham menos valor que o total maior das vantagens desfrutadas por muitos. No entanto, Ngoenha (2004: 121) entende que a justiça não consiste no simples respeito mecânico pelos indivíduos e pelo Estado de certas regras formais, mas pressupõe igualdade de oportunidades, e responsabilidade perante os menos afortunados, isto é, a diminuição das assimetrias sócias (ricos e pobres), devendo ser uma justiça distributiva no que cerne a economia, e a unidade nacional na diversidade cultural.

\section{PlaneAMENTO PASSO-A-PASSO}

A engenharia social utópica, diferentemente da social, recomenda a reconstrução social como um todo. Por isso, fica incapacitada para controlar as consequências reais de cada proposta de mudança, incapacitada ainda de corrigir essas propostas quando as consequências se revelam indesejáveis. Contrariamente a essa perspectiva, Popper (1974: 177) recomenda que as instituições sejam reguladas por uma engenharia social gradual (passo-a-passo), que aborde os problemas um-a-um e experimente soluções bem delimitadas para cada um. Esta engenharia gradual nada mais é, segundo Popper, do que a aplicação do método experimental à sociedade, que pressupõe o método do ensaio e do erro fundado em experiências cruciais devidamente controladas que visam testar hipóteses audaciosas. Sendo assim, se tomarmos a postura da engenharia social gradual, como um critério adequado para resolver o problema da crise democrática, ou se pretendermos uma reforma das instituições, então essa hipótese ao nosso ver parece ser razoável, porque leva-nos a tomarmos uma postura para a resolução dos problemas gerais, para resolver de forma gradual (passo-a-passo). Isso significa, que é erróneo a tentativa de implementar um modelo ideal para uma sociedade (como a Moçambicana), marcada pelas diferenças entre grupos humanos que por sua vez possuem interesses, opiniões e objectivos divergentes. Isso porque a 
democracia, segundo Touraine (2008: 56) esta estreitamente associada ao desenvolvimento endógeno (que se origina no interior do organismo, do sistema, ou por factores internos). Os imaginários para o desenvolvimento não podem ser holísticos, ou seja, não se pode planear de forma total, num país como nosso, que é marcado pela diversidade cultural e de ideias. Então, há uma necessidade de olharmos as diversificadas instituições (existentes nas diferentes culturas) e planearmos de forma autónoma e gradual, em função dos seus imaginários, para permitir um desenvolvimento endógeno (local).

\section{A INTERSUBJECTIVIDADE (O DEBATE CRÍTICO)}

Popper acreditava na possibilidade de uso da atitude crítica, não apenas na prática científica, mas também na área de intervenção social, para Popper nosso conhecimento é falível, assim como as nossas instituições são falíveis, mas que podemos melhorar e nos aproximar do melhor conhecimento possível conforme o caso. Esses melhoramentos decorrem do uso do método crítico que está baseado no racionalismo crítico e na tentativa e correcção de erros. Ou seja, as propostas científicas e práticas de Popper têm como pressuposto a objectividade como resultado da discussão crítica social que permite comparar as tentativas de solução de um problema, bem como encontrar os erros e desenvolver novas tentativas de solução para o mesmo problema. O sucesso ou fracasso da implementação em cada sociedade, para Popper (1993: 132) é mais facilmente avaliado através de mudanças incrementais, e não há nenhuma razão inerente para que esse método conduza a uma acumulação de poder e à supressão da crítica. Porquanto a construção social pode fazer com que,

(...) os políticos começam a olhar para os seus próprios erros em vez de tentar explicá-los e provar que eles sempre foram certos. (...) Este - e não o planeamento utópico ou a profecia histórica - significaria a introdução do método científico na política, já que todo o segredo do método científico é a prontidão para aprender com os erros. (...) A política, eu exijo, deve defender princípios igualitários e individualistas; Os sonhos de beleza têm de submeter à necessidade de ajudar os homens em perigo, e os homens que sofrem injustiça; $E$ à necessidade de construir instituições para servir tais propósitos (Popper, 1957: 163-5).

Com essa proposta crítica, Popper (1993), pretende não só dar ênfase a uma revolução social não violenta, mas também uma reforma social é plausível. Porque somente numa sociedade aberta ao diálogo e ao debate crítico intersubjectivo, ou seja, numa sociedade onde haja à argumentação racional crítica, sem violência e agressão, é que o progresso científico e o avanço social e político tornam-se viáveis. Esta teoria crítica de Popper (1993), confunde-se também ao pensamento de Habermas, através do qual Habermas inspirando-se na teoria transcendental de Kant, substitui a verdade pela validade, um diálogo genuíno. Habermas (1990) não olha pelos interesses egoístas particulares, mas em um interesse comum e a validade de um discurso depende de um consenso, fruto de uma argumentação racional. Com o debate critico Popper busca rebater toda forma de violência e agressão imposta às relações sociais e políticas dos seres humanos. A razão crítica (debate intersubjectivo) é a única forma de combater a violência e a brutalidade. Para isso, é necessário uma 
atitude humana de reciprocidade. E, para se ter boas instituições é preciso que haja pessoas com mentes abertas, isto é, que adoptem uma postura de crítica e incentivem a liberdade de pensamento. E se pretendermos ter uma visão egoísta, ou seja, o factor pessoal, este será um elemento irracional presente nas teorias institucionais e sociais e colocaremos o fim do planeamento (Mingues, 2000: 28).

Em geral, a sociedade aberta invocada por Popper é uma sociedade com condições políticas e sociais aos indivíduos para o exercício da liberdade e de crítica, permitindo, assim, a gradual alteração de leis e costumes através da crítica racional, uma vez que as leis não são eternas ou imutáveis. Para Popper (1957: 122-3), a principal tarefa dos Engenheiros sociais (políticos) é delinear as instituições sociais. Esses engenheiros devem considerar as instituições de um ponto de vista funcional, quer dizer, as instituições são não meios para conseguir determinados fins, mas são avaliadas de acordo com a sua adequação, eficiência e simplicidade para alcançálos. Por isso, Popper (1957: 24) afirma que essas instituições não podem ser consideradas apenas como meios, porque elas se modificam de forma similar equiparadas ao crescimento de um organismo, isto é, apresentam mecanismos, não previstos em sua origem, de selecção e adaptação ao ambiente. Popper sugere ainda que o factor humano seja o elemento incerto na política, porque toda tentativa de controlo pode levar-nos à tirania e ao totalitarismo, conforme ele diz "O controle holístico, é a igualdade não dos direitos humanos, mas das mentes humanas, o que significaria o fim do progresso" (Popper, 1957: 88). Uma sociedade aberta, como defende Popper, desenvolve a liberdade individual e as instituições políticas participativas e não autoritárias, ou seja, as pessoas podem participar livremente nas diversas decisões sociais como agentes críticos e responsáveis. Isso é possível porque tal sociedade confia "na democracia e nas tradições e valoriza o racionalismo crítico" (Idem).

A intersubjectividade é um factor crucial para o alcance da liberdade de pensamento, isto porque as instituições políticas são responsáveis para salvaguardar a liberdade de pensamento sobre a democracia (Popper, 1993: 73-87). Pressupõe-se então que nas sociedades democráticas, é inaceitável a impossibilidade de discussão crítica como acontece nas práticas holistas e utopistas. Estas últimas, poderiam ser enfrentadas por instituições sociais favoráveis, tais como os sistemas educacionais, interessadas em promover a diversidade, e não a uniformidade de mentes humanas (dogmatismo). Razão pela qual, uma das características da engenharia social é de apontar aquilo que não pode ser concretizado. Portanto, os elementos acima mencionados são considerados importantes num Estado liberal democraticamente maduro, são elementos que também liga-se inteiramente à diversidade de projectos individuais de vida, decorrente das diferentes convicções religiosas, filosóficas e morais professadas por cada uma das pessoas em prol da boa convivência política, porque a engenharia social constitui a hipótese de um governo liberal que pressupõe críticas para o seu desenvolvimento.

\section{CONCLUSÃO}

A abordagem de engenharia social de Popper é um contributo importante para acostagem de reformas democráticas, principalmente em países em desenvolvimento, 
como é o caso de Moçambique onde a democracia apresenta enormes deficiências. Daí que há necessidade de reformarmos as nossas instituições para inventarmos uma democracia que seja um governo de povo no respeito pelo povo, das suas representações.

A engenharia social de Popper, propõe que, em Moçambique para que haja uma democracia capaz de criar uma atmosfera de igualdade, deliberdade e o desenvolvimento é fundamental que ela se funde no liberalismo, isto é, a democracia liberal. Dado que, a democracia liberal é diferente da democracia representativa, conforme assiste-se. Na democracia liberal a soberania não pode ser representada, mas sim partilhada, o cidadão deve participar activa e directamente para que a democracia não se transforme em uma ditadura. Antes do mais, esta democracia devese fundar em nossos traços culturais. Há necessidade de inventarmos um modelo institucional que se inspire nos nossos substratos culturais e de imaginários colectivos. Entretanto, as instituições moçambicanas devem se fundar na nossa cultura. São as culturas que vão alimentar as instituições para inventar um modelo de sociedade que nos seja próprio, um modelo capaz de mobilizar o conjunto de cidadãos a participarem não só nas eleições, mas na vida integral da sociedade.

Outrossim, a engenharia social de Popper conjectura que a democracia deve ser vista como um conjunto de instituições. O que significa, que as instituições, em nosso contexto, devem ser mais fortes em relação aos políticos. Para evitar-se abusos de poder. E, Popper entende que as nossas instituições podem ser aperfeiçoadas através da possibilidade de separação de poderes do estado (Executivo, legislativo e Judiciário), com intuito de proteger as liberdades e para que o poder não tome uma feição instrumental, tal como acontece em Moçambique. A não separação de poder implica a ausência da democracia, por isso, há necessidade de limitarmos e dividirmos o poder.

A engenharia de Popper concebe que o estado deve intervir na economia para proteger os economicamente fracos contra os economicamente fortes e proteger a ruina económica. Popper acredita na intervenção social, Popper propõe o debate crítico intersubjectivo. Uma vez que o conhecimento humano é falível, também as nossas instituições são falíveis, mas podemos melhorar através do debate critico, que permite comparar as tentativas de solução de um problema, bem como encontrar os erros e desenvolver novas tentativas de solução para o mesmo problema. O que permitirá um espaço para uma revolução social não violenta. Porque somente uma sociedade aberta ao diálogo e ao debate crítico intersubjectivo, o progresso científico e o avanço social e político tornam-se viáveis.

A justiça social é outro elemento importante na engenharia social de Popper, para o melhoramento das instituições. Facto que pressupõe que deve se fundamentar, também, na ideia de justiça social, como primeira virtude das instituições: a justiça como equidade. Uma justiça capaz de impedir o desenvolvimento das desigualdades. A justiça Social capaz de permitir igualdade de oportunidades e responsabilidade perante os menos afortunados, a diminuição das assimetrias sociais (ricos e pobres). Uma vez que a nossa sociedade é caracterizada por uma diversidade cultural, a engenharia social gradual (passo-a-passo), que aborda problemas um-a-um e que experimente soluções bem delimitadas para cada uma das sociedades existentes em 
Moçambique seria fundamental no contexto de reformas politicas. Entretanto, os imaginários para o desenvolvimento devem ser endógenos.

\section{BIBLIOGRÁFIA}

Bobbio, Norberto (1984). Dicionário de Politica. Carmen C. Varriale, Gaetano Lo Mônaco, João Ferreira, Luís Guerreiro Pinto Cacais e Renzo Dinia (Trad.). 11.ed., São Paulo: UnB.

- (1992). Liberalismo e democracia. Marco Aurélio Nogueira (Trad.). São Paulo: Brasiliense.

Espada, João Carlos. Análise social, a sociedade aberta e o neoliberalismo. 2008. Disponível.em:http://analisesocial.ics.ul.pt/documentos/1223301831F6yXQ4cz3T p19ZD5.pdf.

Foucault, Michel (2008). Nascimento da biopolítica. São Paulo: Martins Fontes.

Fukuyama, F. (1992). O fim da História e o último homem. Rio de Janeiro: Rocco.

Harbermas, Jürgen (1990). Pensamento pós- metafisico. São Paulo: Tempo Brasileiro.

Mazula, Brazão (2006). Na esteira da academia: razão, democracia e educação. Maputo: Textos editors.

Morin, Edgar (1989). O método II: vida da vida. Maria Gabriela de Bragança (trad.). 2. ed., Portugal: Publicações Europa América.

Montesquieu, Charles-Luis de Secondat (1993). O espírito das leis. São Paulo: Abril Cultural.

Mingues, Sofia (2000). Filosofia da Linguagem: uma introdução. Porto: Faculdade de letras da Universidade de Porto.

Nyasani, Joseph M. (2010). Philosophy of Development: An African perspective- reflections on why Africa may never develop on the Western model. Nairobi: Consolata Institute of Philosophy.

Ngoenha, Severino (2004). Os tempos da filosofia. Maputo: Imprensa universitária,

— (2014). Das independências as liberdades. Maputo: Paulinas.

Ilungu, P.E.A (1998). Tradition africaine et rationalité Moderne. Paris: L'Hermattan.

Touraine, Alain (2008). Crítica da Modernidade. Petrópolis: Vozes.

Popper, K. Raimund (1974). A sociedade aberta e seus inimigos. Milton Amado (Trad.). São Paulo: Belo Horizonte.

— (1945). Lógica da Investigação Científica. São Paulo, Abril Cultural (Colecção Os pensadores).

— (1982). Conjecturas e refutações. Brasília: Editora da UnB.

— (1957) A Miséria do Historicismo. São Paulo: Cultrix. 
- (1993). O racionalismo crítico na política. Maria da Conceição (Trad.). 2. ed., Brasília: Côrte-Real.

Sen, Amartya (2010). Desenvolvimento como liberdade. Laura Teixeira Motta (trad.), São Paulo: Schwarcz, Ltd.

Rousseau, Jean-Jaques (1999). O contracto Social. António de P. Machado (Trad.). 19. Ed., Rio de Janeiro: Itabuna.

Rawls, John (2000). Uma teoria de justiça. Almiro Pisetta e Lenita M. R. Esteves (Trad.), São Paulo: Martins fontes. 